\title{
DISTRIBUTIVE JUSTICE AND HUMAN RIGHTS IN CLIMATE POLICY: THE LONG ROAD TO PARIS
}

\author{
Idowu Ajibade*
}

\begin{abstract}
The Paris Agreement, adopted by 196 countries, is the first global climate change instrument to explicitly reference human rights as a guiding principle. The treaty does not expound on the implications of climate change for human rights but the fact that it calls on State Parties to respect human rights when combating climate change shows a significant improvement in international thinking and acceptance of the linkages between human rights and climate change. Indeed, this is no mean feat. The journey to Paris has been a long and arduous process, especially for the broad coalition of indigenous people, gender, human rights, environmental and climate justice groups that worked tirelessly to bring the issue to global focus. My goal in this article is to explore the implications of a human rights clause in the Paris Agreement. Does it carry any legal or political weight? Are State Parties likely to operationalize it? In what ways can they enforce this part of the Agreement? To answer these questions, this article traces the historical account of the connections between human rights and climate change within the United Nations system and examines issues of equity and distributive justice in international climate change frameworks such as the UNFCCC, Kyoto Protocol, and the Paris Agreement. The article expounds on opportunities for integrating human rights-based approaches into national and international climate policy and concludes on the need for further integration of both issues in future research and treaty negotiations.
\end{abstract}

Keywords: Climate change, human rights, justice, policy, Paris Agreement

DOI: http://dx.doi.org/10.4314/jsdlp.v7i2.4

\section{INTRODUCTION}

The multiple implications of climate change for human rights have

* Postdoctoral Fellow, Balsillie School of International Affairs, Waterloo, Canada. jajibade@balsillieschool.ca. 
been extensively discussed in the literature. ${ }^{1}$ Extreme weather events such as increases in temperature or decreases in rainfall could lead to droughts in areas where people already suffer from severe hunger and malnutrition. ${ }^{2}$ Infectious diseases that often accompany extreme weather events (such as flooding) may affect women and children's right to health. ${ }^{3}$ Also, the decline in food supply due to climate-induced drought may increase hunger and malnutrition in vulnerable communities, thus affecting their right to food. Sea level rise and possible inundation of towns and nations could result in statelessness and cause millions of people to become environmental refugees. ${ }^{4}$ Despite these connections between global climate change and human rights, it was not until the late 2000s that the debate on climate change was framed within a human rights discourse. The 2007 Bali Conference of Parties (COP) was the first high-level governmental meeting where Kyung-wha Kang, the UN Deputy High Commissioner for Human Rights, expressed the connection between human rights and climate change. She stated in her remarks that:

There are many predictions that global warming could result in hundreds of millions of people suffering from hunger, malnutrition, water shortages, floods, droughts, heat stress, diseases triggered by extreme weather events, loss of livelihoods and permanent displacement. These human consequences are already visible and real in many corners of the world. The human rights approach

1 Damilola Olawuyi, The Human Rights Based Approach to Carbon Finance (Cambridge University Press, 2016) 1-25; Simon Caney, 'Human rights, climate change, and discounting' (2008) 17 (4) Environmental Politics, 536-555; Jon Barnett, 'Human rights and vulnerability to climate change'. In S. Humphreys (ed.), Human rights and climate change (Cambridge University Press 2010) 257-271; D Bell, 'Does anthropogenic climate change violate human rights?' (2011) 14 (2) Critical Review of International Social and Political Philosophy 99-124.

2 Nicholas Stern, The economics of climate change: The Stern review (Cambridge University Press, 2007).

3 Idowu Ajibade, Gordon McBean, and Rachel Bezner-Kerr. 'Urban flooding in Lagos, Nigeria: Patterns of vulnerability and resilience among women.' Global Environmental Change 23.6 (2013): 1714-1725.

4 Koko Warner, 'Global environmental change and migration: Governance challenges' (2010) 20 (3) Global environmental change 402-413; Mortreux, C., \& Barnett, 'Climate change, migration and adaptation in Funafuti, Tuvalu,' Global Environmental Change (2009) 19(1) 105-112. 
compels us to look at the people whose lives are most adversely affected and to urge governments to integrate their human rights obligations into policies and programs to deal with the climate change as well as to the international community to assist in this process. $^{5}$

The United Nations Human Rights Council (UNHRC) reiterated this connection on 28 March 2008, when the Council adopted Resolution 7/23 calling for a detailed and analytical study on the relationship between human rights and climate change, to be undertaken by the Office of the High Commissioner for Human Rights (OHCHR). ${ }^{6}$ The outcome of the study included submissions from states and NGOs along with other scholarships devoted specifically to help advance the conceptual and legal underpinning of the question of human rights and climate change. The report of this study, which came out in 2009, led to the adoption of Resolution 10/4 where UNHRC recognized:

that the adverse effects of climate change have a range of direct and indirect implications for the effective enjoyment of human rights and the effects of climate change will be felt most acutely by those segment of the population that are already vulnerable owing to geography, gender, age, indigenous or minority status, or disability. ${ }^{7}$

The United Nations Framework Convention on Climate Change (UNFCCC) up until the Cancun Accord in 2010 did not mention human rights. The UNFCCC (COP 15) made reference to justice and rightsbased concerns in the Copenhagen Accord but not in any strong language. The Accord called for an imperative need to act based on equity and also recognized the critical impacts of climate change and

5 OHCHR Statements on human rights and climate change. <www.ohchr.org/ EN/Issues/HRAndClimateChange/Pages/Statements.aspx $>$ accessed 10 October 2016.

6 Human Rights Council Res. 7/3 (2008) 4. On the relationship between climate change and human rights; see also ICHRP (2008). Climate change and human rights: a road map. Geneva, Switzerland: ICHRP.

7 Office of the UN High Commission for Human Rights (OHCHR), Report of the Office of the UN High Commissioner for Human Rights on the Relationship between Human Rights and Climate Change (UN Doc. A/HRC/10/61: 15 Jan. 2009). 
potential impacts of response measures on vulnerable communities. ${ }^{8}$

In the Cancun Agreements (COP 16), the UNFCCC noted the UNHRC Resolution 10/4 on human rights and also emphasized in paragraph 8 that State Parties should, in all climate change-related actions, fully respect human rights. In the lead up to the Cancun Agreement, the UNHRC specifically placed emphasis on working together with the UNFCCC secretariat and informing the UNFCCC parties of its proceedings. In its Resolution 10/4, the Council announced its decision to welcome the exchange of information between the OHCHR and the UNFCCC secretariat. ${ }^{9}$ It also requested the OHCHR to release the outcomes of discussions and workshops organized by the UNHRC on this issue to the UNFCCC-COP. ${ }^{10}$ These efforts resulted in the establishment of an Ad hoc Working Group on Long-term Cooperative Action between the two organizations. ${ }^{11}$ Arguably, the collegial efforts of the UNHRC office combined with the advocacy of civil society and other activist groups culminated in UNFCCC State Parties' decision to explicitly include and acknowledge human rights in the preamble text of the Paris Agreement. ${ }^{12}$ It is pertinent to ask: what weight does a human right clause carry in the Agreement? Will State Parties operationalize it in their national jurisdictions? Will it translate into meaningful protection for vulnerable groups, especially the indigenous communities whose rights have been violated persistently through climate change adaptation and mitigation projects? I address these issues in the sections below.

This article is divided into five sections. The following section examines the equity and moral linkages of climate change and human rights through a distributive justice lens, while the third section explores the legal weight of human rights in the Paris Agreement as well as

8 Report of the Conference of the Parties on its fifteenth session United Nations Framework Convention on Climate Change (held at Copenhagen, Denmark, 7-19 December 2009). FCCC/CP/2009/11/Add.1 30 March 2010. <http:// unfccc.int/resource/docs/2009/cop15/eng/11a01.pdf > accessed 10 October 2016.

9 Human Rights Council (HRC), Resolution 10/4 - human rights and climate change. (Tenth Session, Human Rights Council 2009) < http://ap.ohchr.org/ documents/E/HRC/resolutions/A_HRC_RES_10_4.pdf $>$ accessed 10 October 2016.

10 Human Rights Council Resolution 18/22, 2011.

11 HRC (n 8).

12 Hereafter referred to as the Agreement. 
other progress and shortcomings in the Agreement. The fourth section suggests ways of integrating human rights-based approach into the national climate policy, and the final section provides direction for future academic research and treaty negotiations.

\section{DISTRIBUTIVE JUSTICE, UNFCCC AND PARIS}

Global environmental problems such as climate change raise considerable ethical challenges when issues of justice and human rights are examined. Owing to the implications of climate change on different geographical and temporal scales, three dimensions of distributive justice can be explored. First, there are questions of the distribution of burdens and resources among countries; that is who is responsible for the large-scale impact of climate change? Who will be harmed? And who has the capacity to mitigate or adapt to emerging and future changes in the global climate system? These questions are related to the issues of historical responsibility, burden sharing, and differential obligations recognized in the United Nations Framework Convention on Climate Change (UNFCCC) and its Kyoto Protocol. ${ }^{13}$

Evidence from the assessment reports of the Intergovernmental Panel on Climate Change (IPCC) ${ }^{14}$ suggests that the high concentrations of GHG emissions in the atmosphere were a result of the industrial revolution in the last 50 years. Emissions from fossil fuel, land-use change, and agriculture, have led to significant increase in the greenhouse gases that are driving climate change. ${ }^{15}$ Given their overall

13 Timmons Roberts and Bradley C. Parks, 'Fueling injustice: globalization, ecologically unequal exchange and climate change' (2007) 4(2) Globalizations 193-210.

14 Houghton, J. et al., 'IPCC 2001: Climate Change 2001' (The Climate Change Contribution of Working Group I to the Third Assessment Report of the Intergovernmental Panel on Climate Change 2001) 159; Parry Martin L et al, 'IPCC, 2007: climate change 2007: impacts, adaptation and vulnerability' (Contribution of working group II to the fourth assessment report of the intergovernmental panel on climate change 2007) 1-976; Seneviratne, Sonia I et al, 'Changes in climate extremes and their impacts on the natural physical environment' (Managing the risks of extreme events and disasters to advance climate change adaptation 2012) 109-230; Pachauri, R.K. (ed) 'Climate Change 2014' (Synthesis Report: Contribution of Working Groups I, II and III to the Fifth Assessment Report of the Intergovernmental Panel on Climate Change IPCC 2014).

15 ibid. 
and higher per capita emissions, industrialized countries are deemed responsible for current GHG concentrations in the atmosphere and therefore charged under the UNFCCC and the Kyoto Protocol with the obligation to take the lead in climate change mitigation and also to support developing countries in adaptation efforts. ${ }^{16}$ The UNFCCC and its Kyoto Protocol, which are the primary mechanisms for co-ordinating international action on climate change through mitigation and adaptation contains an expression of distributive justice in that they call for 'common but differentiated responsibility and respective capabilities' (CBDR-RC) concerning addressing climate change at the global scale. ${ }^{17}$ This principle led to 'developed' and 'developing countries' being assigned as Annex 1 and non-Annex 1, respectively, under the Kyoto Protocol, with Annex 1 countries given binding targets.

The Paris Agreement, which replaces the Kyoto Protocol when it expires in 2020, makes no such distinction. Instead, it expresses a softening of the original principle of equity and CBDR-RC. The Agreement calls for 'equity and CBDR-RC in the light of differentiated national circumstances' as opposed to the initial idea of historic responsibility. In effect, it disregards the injustice of the causation of climate change and the slightly heavier mitigation duties of developed nations. Thus, under appreciating the disproportionate burden of climate change on those least responsible and with the least resources, but most likely to be affected, such as African countries and low-lying Small Island states.

The second aspect of distributive justice in climate change is in the area of adaptation. No matter what happens with mitigation, some form of adaptation will be required because of the current degree of warming to which the world is already subjected due to past emissions. The justice arguments here are in two folds. One is that under UNFCCC and the Kyoto Protocol, developed nations have obligations to assist developing countries in adapting to climate change through finance, technological transfer, and capacity building. As part of the efforts to meet the Kyoto targets, an Adaptation Fund (AF) was set up in 2001 to finance concrete adaptation projects and programmes in developing countries party to the Protocol, particularly those vulnerable to the

16 United Nations, UN Framework Convention on Climate Change (UNFCCC New York 1992); United Nations; Kyoto Protocol (United Nations framework convention on climate change, Kyoto Protocol, Kyoto 1997).

17 ibid. 
adverse effects of climate change. The AF is financed with a share of proceeds from the Clean Development Mechanism (CDM) project activities as well as through voluntary pledges of donor governments. ${ }^{18}$ To date US\$354 million has been disbursed towards adaptation activities and about 61 countries were beneficiaries - translating into 3.61 million direct beneficiaries, ${ }^{19}$ which is less than one-third of the population of the city of Lagos (a city vulnerable to flooding) or onefourth the population of Malawi (a country severely affected by drought). To be clear, the need in developing countries is much greater than the adaptation support received so far. Finance for Adaptation under Paris Agreement is unclear. Article 6 (6) of the Agreement states that a share of the proceeds from a new mechanism for mitigation of greenhouse emissions and sustainable development will be used to assist vulnerable developing countries to meet the costs of adaptation. ${ }^{20}$ Whereas in Article 6 (1), the treaty makes the contributions toward the new fund voluntary with no specific targets. ${ }^{21}$ This new fund is expected to be the successor to the CDM, which was highly criticized for contributing to some hydroelectric and other projects that were linked to human rights abuses, including displacement of indigenous and other communities without transparency or adequate consultation. ${ }^{22}$

Another scale of distributive justice in adaptation is at the national level. Since the ability to adapt to climate change is socially differentiated among countries, communities and people, managing the consequences of the distribution of climate change impacts will require responsive governance at the national and provincial level. It will also require taking into consideration issues of economic globalization, historical disadvantages (e.g., colonialism), political and environmental constraints, social conflicts and prevailing institutional structures and opportunities in societies. States have a 'duty' to ensure

18 Adaptation Fund 2016 <https://www.adaptation-fund.org/> accessed 20 September 2015.

19 ibid.

20 The Paris Agreement (n 11).

21 The Paris Agreement (n 11).

22 OHCHR, 'No time for complacency' (UN rights expert says as the Paris Agreement faces its first key test). <http://www.ohchr.org/EN/NewsEvents/Pages/ DisplayNews.aspx?NewsID $=19962 \&$ LangID $=\mathrm{E}>$ accessed 20 September 2015. 
equitable and fair adaptation among their people. They are expected to remedy existing inequalities that may exacerbate the potentially catastrophic effects of climate change on the economically and politically marginalized and also create new policies that can facilitate the capacity of vulnerable groups to adapt to climate change. Such policies may involve spending more money on the following types of activities: building sea-walls to protect those who live and work near the coast from sea-level rise and from storm surges; subsidizing people to move away from threatened coastal settlements; spending more money to inoculate people from infectious diseases; and supporting irrigation systems in drought-prone areas. ${ }^{23}$

A third aspect of distributive justice in climate change raises questions about intergenerational justice. First, the ill effects of the high GHG emissions of the current generation will be borne by future generations. Second, part of the problem facing current and future generations arises because of the policies and actions of past generations. ${ }^{24}$ To highlight the equity issues underlying intergenerational burdens of climate change, Stern uses a low discounting rate to calculate the possible damage of future climate change and its impacts on people. ${ }^{25} \mathrm{He}$ calculated marginal climate change damages for GHG emissions pathways based on 'business-asusual' as well as residual climate change damages for other emissions pathways - (e.g. a pathway associated with a 450ppm of $\mathrm{CO}_{2}$ emissions). He concluded that there is a strong economic reason for countries to aggressively cut emissions, as the cost of adaptation in the future will be higher. ${ }^{26}$ Although Stern was criticized for using the lowest possible discount rate to address the problematic assumptions about conventional discounting of future harm ${ }^{27}$ his work proved to have influenced intergenerational equity discourse on climate change such that many scholars now accept that the effect of climate change

23 Caney, Simon, 'Human rights, climate change, and discounting' (2008) 17 (4) Environmental politics 536-555; Barnett (n 1).

24 ibid.

25 Stern (n 2).

26 Ibid.

27 Eric Neumayer, 'A missed opportunity: The Stern Review on climate change fails to tackle the issue of non-substitutable loss of natural capital' (2007) 17 (3) Global environmental change 297-301; William Nordhaus, 'A review of the Stern review on the economics of climate change' (2007) 45 (3) Journal of economic literature 686-702. 
will harm future persons (generations). However, what is highly debated is whether future persons have rights, including how they have human rights now with regards to such issues, and whether such rights imposes a correlative duty on current generations. ${ }^{28}$ The issue of intergenerational equity was not discussed in the Paris Agreement other than being mentioned under the human rights clause as a consideration for States when taking actions to address climate change.

\section{PROGRESS AND SHORTCOMINGS IN THE PARIS AGREEMENT}

The Paris Agreement has been hailed as an ambitious and far-reaching response by governments of the world to tackle climate change. It not only mandates limiting global temperature rise to 1.5 degrees Celsius above pre-industrial levels (well below the original 2 degree goal) but calls for the protection of human rights and gender equality. The Agreement in its preamble states:

Acknowledging that climate change is a common concern of humankind, Parties should, when taking action to address climate change, respect, promote and consider their respective obligations on human rights, the right to health, the rights of indigenous peoples, local communities, migrants, children, persons with disabilities and people in vulnerable situations and the right to development, as well as gender equality, empowerment of women and intergenerational equity. ${ }^{29}$

Indeed this is a laudable step, but as Mayer noted, the Agreement does not create any self-standing human rights-related obligations. ${ }^{30}$ While it contributes to the development of a political narrative justifying climate action by reference to human rights, the direct impact on the protection of human rights in climate action is limited because the Agreement specifies no concrete implementation measures. More so, since human rights were mentioned solely in the preamble, it is not

28 Bell (n 1) 99-124.

29 The Paris Agreement 2015 <http://unfccc.int/paris_agreement/items/9485. php $>$ accessed 10 September 2016.

30 Benoit Mayer, 'Human Rights in the Paris Agreement' (2016) 6 (1/2) Climate Law 109-117. 
self-operational without further interpretation. This, in part, is because it may not be immediately apparent how human rights should be applied in unforeseen climate events or policy contexts. Under such circumstances, the Vienna Convention on the Law of Treaties states that treaties are to be interpreted 'in good faith' and according to the 'ordinary meaning given to the terms of the treaty in their context and in the light of its object and purpose'. ${ }^{31}$ Hence, having the human rights clause in the preamble section should guarantee its implementation in good faith.

Furthermore, preambles contribute to the formation of customary norms under international law (ILO) and in many jurisdictions, their legal status varies from symbolic to interpretative and substantive. ${ }^{32} \mathrm{~A}$ survey of the function of preambles shows a growing trend toward its having greater binding force - either independently, as a substantive source of rights (e.g. in France and Nepal), or as a guide for constitutional interpretation (e.g. in Estonia, Macedonia, Ukraine and Germany). ${ }^{33}$ This means that the human rights clause could have some legal force in certain countries that are party to the Paris Agreement particularly in States where preambles are given a strong force rather than symbolic values. Indigenous people could perhaps also invoke this clause at the national level to ensure that proposed climate mitigation and adaptation projects do not violate their human rights or adversely affect their communities. The overarching benefits of having human rights in the Paris Agreement is that there will be no international cooperation for transnational projects that violate or disregard populations concerned. ${ }^{34}$

Another positive note in the Paris Agreement is the reference to gender-responsiveness in adaptation and capacity building ${ }^{35}$ and the provision of enhanced and robust transparency framework. ${ }^{36}$ These elements can contribute to improved accountability in adaptation and mitigation actions and projects.

31 United Nations, Vienna Convention on the Law of Treaties (United Nations, Treaty Series, vol. 1155 1969).

32 Liav Orgad, 'The preamble in constitutional interpretation' (2010) 8 (4) International Journal of Constitutional Law 714-738.

33 ibid.

34 Benoit Mayer (n 28).

35 The Paris Agreement, article 7 (5) and 11 (2).

36 The Paris Agreement, article 4 (13) and Article 13 (1). 
Notably, a major drawback in the Agreement is the absence of the concept of equity and justice in its substantive component. The Agreement essentially absolved developed nations of their historical responsibility without putting forward any 'clear, meaningful and binding' target for individual countries to cut emissions or finance adaptation in developing nations. The text does talk about support for loss and damage but specifies that this will not be considered as liability or compensation. Furthermore, the treaty makes provision for a global stocktake, ${ }^{37}$ which refers to a proposed five-yearly review of the impacts of countries climate change actions, with the first evaluation falling due in 2023. The stocktake will not be an assessment of individual countries' contribution but a collective analysis of what has been achieved in combating climate change and what more needs to be done. This new approach which shifts focus from 'who should listen to what' and solely to 'what needs to be done' further weakens the obligations of developed nations and erases their responsibilities for dealing with the consequences of their past emissions.

By November 2016, the Paris Agreement will officially enter into force, which means that at least 55 parties representing at least 55 per cent of global emissions have ratified the treaty. ${ }^{38}$ Major emitters such as the United States and China have also signed the Agreement but are yet to ratify it. Both nations create nearly 38 per cent of the world's emissions. ${ }^{39}$ Since the Agreement is not legally binding, it remains to be seen whether its entry into force will have any significant impact in combating climate change. This weakness could also render the human rights clause in the Agreement symbolic even if it hypothetically has some enforcement thrust.

\section{PROMOTING HUMAN RIGHTS-BASED APPROACH IN NATIONAL CLIMATE POLICY}

The Paris Agreement is not perfect and cannot be expected to address

37 The Paris Agreement, article 14.

38 UNFCCC, The Paris Agreement-status of Ratification < http://unfccc.int/ paris_agreement/items /9444.php> accessed 20 September 2016.

39 Carole lee and William Mauldin, U.S., China Agree on Implementing Paris Climate Change Pact. 2016. The Wall Street Journal. http://www.wsj.com/ articles/u-s-china-agree-on-implementing-paris-climate-change-pact1472896645 . 
the gaps between climate change and human rights fully. Further integration between the two issues can be achieved at the national scale and through creative legal and non-legal processes. One approach is to connect human rights and the environment to efforts aimed at establishing a free-standing right to a clean and healthy environment. ${ }^{40}$ Under this approach, actions such as pollution and oil spillages that contribute to environmental deterioration and degradation, which may threaten human life and health, are to be considered a violation of human rights. For example, in the case Gbemre v. Shell Petroleum Development Co., the plaintiffs alleged that the environmental impacts of gas flaring and its climate change implications were affecting their rights to life and to a healthy environment. The Federal High Court of Nigeria, in a ruling on 14 November 2005, upheld the plaintiff's claim, ordering Shell and the Nigerian National Petroleum Corporation 'to take immediate steps to stop the further flaring of gas in the plaintiff's community'. ${ }^{41}$ The Gbemre case is certainly one of the important developments in the jurisprudence regarding the constitutional human right to environment in Nigeria. ${ }^{42}$ Even though little analysis of the plaintiff's climate change claims accompanied the court's ruling, the case holds possibilities for crafting legal approaches to climate change through claims about rights to the environment. ${ }^{43}$

40 African Charter on Human and Peoples' Rights (ACHPR, Adopted June 27, 1981, came into force Oct. 21, 1986); Declaration, Rio, 'Rio declaration on environment and development (1992); D Shelton, 'Human rights, environmental rights, and the right to environment' (1991) 28 Stan. J. Int'l L. 103-138; Alan Boyle, 'The role of international human rights law in the protection of the environment' (1996) 43 Human rights approaches to environmental protection 48.

41 Suit No. FHC/CS/B/153/2005. Gas flaring in Nigeria has contributed more greenhouse gas emissions than all other sources in sub-Saharan Africa combined, as well as poisoning local communities. The Federal High Court held that the gas flaring was a gross violation of constitutionally guaranteed rights to life (including health environment) and dignity of human person. This was the first time that a Nigerian court has applied the rights to life and dignity in an environmental case.

42 Kaniye Ebeku, 'Constitutional right to a healthy environment and human rights approaches to environmental protection in Nigeria: Gbemre v. Shell revisited' (2007) 16 (3) Review of European Community \& International Environmental Law 312-320.

43 Amy Sinden, 'Climate change and human rights' (2007) 27 J. Land Resources \& Envtl. L. 255. 
A second approach is to mainstream human rights into all climate change policies, projects, and activities at the national, city and municipal levels. This approach might involve the application of procedural rights such as the right to information, right to participation in decision making, and access to justice in a climate change and environmental matters (UNECE 1991; Atapattu, 2006). An example of this approach can be found in environmental impact assessment litigation in Australia. In the case Gippsland Coastal Board $v$ South Gippsland Shire Council (2008), the Gippsland Board challenged the local Council's decision to grant residential development in a coastal region, arguing that the proposed development was inappropriate in light of projected sea level rise as a result of climate change. The Court applied a precautionary principle and determined that the development consent should not be granted on account of the reasonable foreseeable risk of inundation of the site and proposed dwelling due to sea level rise. This procedural approach is considered to be a potentially less contentious way of mainstreaming human rights norms into climate change policies.

A third approach focuses more on issues of discrimination and unequal power relationships that increase peoples' vulnerability to climate change impacts. ${ }^{44}$ This approach notes that climate change will affect various human rights, including the rights to life, food, housing, shelter, and culture, but greater weight is placed on issues of marginalization and other forms of pre-existing injustices that heighten the vulnerability of people under a changing climate. The central thesis of this perspective is that there is a multiplication of human rights infringements, not caused by the physical events of climate change, but by the social, economic, and political processes that make people vulnerable or unable to cope with the impacts of those events. ${ }^{45}$ In some countries, for example, poor neighbourhoods are targeted as potential locations for toxic waste, which could worsen the already poor standard of living and human rights conditions in those communities, thus making them even more vulnerable to the impact of climate change. Under human rights law, states are legally bound to address such vulnerability in accordance with the principle of equality and non-discrimination. ${ }^{46}$

44 OHCHR (n 6) paragraph 95.

45 Barnett (n 1).

46 OHCHR (n 6) Paragraph 42. 
The vulnerability approach also recognizes that measures to mitigate or adapt to climate change may infringe on human rights. ${ }^{47}$ For instance, the reliance of some nations on maize as bio-fuel could potentially increase people's vulnerability to food insecurity. Also, certain flood mitigation measures in coastal areas may create new vulnerabilities or lead to outright displacement of poor communities, thereby affecting their rights to housing and security. An example is the displacement of Kuramo residents in the wake of the construction of the Eko Atlantic city in Lagos. A number of scholars has discussed this understanding of rights-based approach to vulnerability reduction in the context of climate change. ${ }^{48}$ To enhance synergy, states need to consider a more integrated approach to climate change, disaster riskreduction, and human rights protection. Such an approach will enhance knowledge about differential vulnerability and allow governments to reflect these differences in considerations of resource allocation, emergency planning, and policy response.

Since climate justice is an obligation for a change, not just rights, the vulnerability approach is not so much about the legal protection of human rights but for social change and political strategies that are necessary to scale up adaptive capacity and resilience among vulnerable groups and communities. An implication of this discussion is that in places where there are gross violations of human rights, like those occurring in conflict zones such as Syria or in highly repressive regimes such as North Korea, actions to promote adaptation may be far less effective in reducing vulnerability than actions to promote the kinds of political freedoms and social opportunities necessary for people to take action themselves to build resilience. ${ }^{49}$ In this case, the largest gains in reducing vulnerability may come from eliminating the most severe human rights violations through strengthening and implementing the protection of a broad spectrum of rights.

47 Stephen Humphreys, Human rights and climate change (Cambridge University Press 2010).

48 James Boyce, 'Let them eat risk? Wealth, rights and disaster vulnerability' (2000) 24 (3) Disasters 254-261; Yamin, Farhana, Atiq Rahman, and Saleemul Huq, 'Vulnerability, adaptation and climate disasters: a conceptual overview' (2005) 34 (4) IDS bulletin 1-14; Sarewitz, Daniel, Roger Pielke, and Mojdeh Keykhah, 'Vulnerability and risk: some thoughts from a political and policy perspective' (2003) 23 (4) Risk analysis 805-810.

49 Barnett (n 1). 
Using the aforementioned human rights-based approaches to climate change, human rights standards can be harmonized and integrated into the planning and execution of national climate policy as well as adaptation and mitigation plans. This way, protection of human rights would not only come to the fore when there is a violation but would also form a part of the 'rules of the game' when designing responses to climate change at the community and state levels. The duty of states to harmonize climate change responses with human rights obligations is well entrenched in the principles of systemic integration and coherent interpretation of international law, laid down in Article 31(3)(c) of the Vienna Convention on the Law of Treaties. ${ }^{50}$ This speaks of a presumption that states, when designing rules, measures and action plans under one treaty obligation, should not violate their obligations under other pre-existing treaties. ${ }^{51}$ As such, when countries design plans and projects on their adaptation and mitigation obligations under the United Nations Framework Convention on Climate Change, the Kyoto Protocol, and the Paris Agreement, the aim should not be to set aside or violate other relevant obligations under international human rights treaties..$^{52}$ After all, human rights are as much about ethical demands, call for social justice, political action, and social transformation, as they are about legal norms and rules. ${ }^{53}$

\section{CONCLUSION}

The cumulative effects of anthropogenic climate change on human rights including individual rights (e.g., the rights of the poor to life and health), groups' rights (e.g., the rights of small island states), and intergenerational rights (e.g., the rights of future generations to a liveable

50 United Nations (n 29).

51 International Law Commission (ILC), 'Fragmentation of International Law: Difficulties arising from the Diversification and Expansion of International Law' (Report of the Study Group of the International Law Commission, 13 Apr. 2006, A/CN.4/L.682) 426).

52 Idowu Ajibade and Damilola S. Olawuyi, 'Climate change impacts on housing and property rights in Nigeria and Panama: Toward a rights-based approach to adaptation and mitigation'. In Elena Lopez-Gunn and Dominic Stucker (Eds.), Adaptation to Climate Change through Water Resources Management: Capacity, Equity and Sustainability (Routledge, New York 2014) 264-284.

53 Edward Cameron, 'Development, climate change and human rights From the Margins to the Mainstream?'(Social development papers, paper No. 123/ March 17. Washington DC: World Bank Publications 2011). 
environment) are crucial climate justice issues which legal scholars, social scientists, and human rights advocates will continue to grapple with. The Paris Agreement is a first step in the international recognition and acceptance of the connections between the greatest environmental crisis of this generation and the most robust protection mechanism we have at the international level. Since the Agreement falls short on equity and justice in its substantive component, subsequent treaty negotiations and interpretation will be required to ensure that the acknowledgement of human rights translates into concrete protection for vulnerable groups and communities adversely affected by climate change.

At the national level, a number of measures can be taken to protect human rights such as mainstreaming human rights into all climate policies, strengthening environmental protection mechanisms, upholding procedural rights and accountability mechanisms, and addressing the social, economic and political drivers of vulnerability and disaster risks. As we look into the future, it is important that human rights practitioners and climate change experts continually work together to ensure that human rights are protected despite the changes in the global climate system as well as efforts taken to mitigate and adapt to these changes. Other social scientists and practitioners from the disaster-risk reduction community must join the bandwagon so they can contribute to knowledge and policy development on how to address the question of vulnerability, equity, and justice in global and national response to climate change. 